\title{
THE LINGUISTIC ANALYSIS OF REPORTER NEWSPAPER ADVERTISEMENT
}

\author{
Abebe Asres Mengistu \\ Assistant Professor of Applied Linguistics and Communication, University of Gondar
}

DOI: $10.37648 / \mathrm{ijrssh} . v 10 \mathrm{i} 01.038$

Received:07 $7^{\text {th }}$ November 2019; Accepted:09 ${ }^{\text {th }}$ December, 2019; Published:29 $9^{\text {th }}$ December, 2019

\begin{abstract}
This study is aimed at the Linguistic Analysis of Reporter Newspaper Advertisements. By using purposive and simple random sampling methods, 20 advertisements are selected from Ethiopian Reporter Newspaper 2008, 2009-and 2010years' publications and analyzed based on Textual Conceptual Functions/TCF. Under this frame work, linguistic means of advertising language has been analyzed interms of phonological andlexical aspects. Accordingly, mnemonic features (rhyme, alliteration, rhythm and assonance), adjectives, noun phrases, verb phrases, ellipses, incompletes, sentence types, idiomatic expressions and their purposes in the meaning development of the advertisements have been analyzed. Hence, most of the sample advertisements used rhyme, assonance, consonance, alliteration (phonological aspects). The other thing that advertisements are used most of the time as a unique feature is adjectives.Adjectives are the most powerful devices of advertisements in order to create desire, interest and persuasion by giving the advertising goods a hyperbolic character. Numerals also used in the sample advertisements to give the accurate number and to catch readers' attention with the advertising goods. Incomplete sentence structures and omissions are also analyzed as the good quality and economic way of the advertisements. On the other hand, imperative and interrogative sentence types are mostly used other than declaratives. Generally, this study has been taken in order to give analysis on the linguistic elements of print advertisements. Hence, deep analysis has been made on the linguistic features of the sampled advertisements. Even though the sample advertisements are made up of textual expressions and visual images, the analysis is focused on only the textual part.
\end{abstract}

Keywords:Lingustic analysis, Reporter Newspaper, Advertisement

\section{INTRODUCTION}

Advertisement is the promotion of goods, services, companies and ideas usually performed by an identified sponsor. It is the activity of attracting public attention to a product or business as by paid announcements in the print, broadcast, or electronic media, and the business of designing and writing advertisements. Advertisement is also a function or tool that is likely to affect most of us in a number of different spheres of our lives. In addition, advertising is a beneficial kind of nonpersonalcommunication executed to promote and publicize an organization and its products. Hence, it can be seen in to three main categories: as consumer 
advertisement, trade advertisement and public relations advertisement (Pride and Ferrell, 1987).

Advertisement has become the part and parcel of ourpresent-day life. In spite of it, there is an attractive power that manipulates the consumer; an invisible voice of advertisement advocates, encourages, asks, announces and deeply embeds into people's mind. Thus,advertisement indicates the differences that exist between brands of products and alternative services. On the other hand, by making people aware of products, services and ideas, advertisement promotes sales and profits (Lapsanska, 2006).

Its history can be traced to ancient civilizations. It became a major force in capitalist economies in the mid$19^{\text {th }}$ century based primarily on newspapers and magazines.Inthe $20^{\text {th }}$ century, advertisement grew rapidly with new technologies; direct mail, radio andtelevision, Internet and smart phones. In light of this, nnowadays, more and more products are entering markets seeking more profits through increasing sales. Producers look for various ways to achieve the best sales by commercial advertisement. They use different means to do that: TV, radio, newspapers, and recently the Internet (El Daly, 2011).

Accordingly, advertisement is everywhere around us, manipulating consumers by its power of attraction. It has an invisible voice which encourages, asks, announces and deeply embeds to people's minds (Lapsanska, 2006). It is no exaggeration to claim that today most of our information and lifestyle models come from, or are related to advertising images. Since the 1920s, image creation has become the primary techniques of what has come to be known as the era of persuasion in advertising. This is an era in which advertising messages have moved away from describing the product in itself to focus on the consumer of the product, creating product imagery with which the consumer can easily identify (El Daly, 2011).

Advertising has a number of features, but in most of them, language and images are of crucial importance. The words in advertisements are carefully structured and images are purposely selected to meet particular needs for social and commercial functions. Together the functions have made advertising very important in the modern world. In fact, advertising is one of the major forces that help to improve the standard of living around the world. Though, advertisements are an inevitable part of everyone's lives; even if one does not read a newspaper or watch television, he/she can't escape from the images posted over our urban surroundings (El Daly, 2011).

To add more,in our country Ethiopia many advertisements are transmitted in different media. Many organizations introduce their goods, services and idea through advertisements. Mostnewspapers and magazines contain many advertisements;it is also usual to see many advertisements even at one television or radio program.

On the other hand, even though there are different advertising media in Ethiopia, many people are not accessible for internet and television to be engaged in advertisements. Additionally, print media is media is not much accessible for advertising goods and servicesto the wider society. But, in Ethiopia print advertisements are being advertised in many newspapers which are published daily, weekly, monthly, and yearly.Among these, as I have seen many publications of 2008 E.C Reporter Newspaper consists more advertisements than other newspapers. Thus, my research is focused on print advertisements those are contained in Reporter Newspaper.

\section{STATEMENT OF THE PROBLEM}

Language is a powerful tool for human beings to communicate one to another. It has a powerful influence over people and their behavior. This is true especially in the fields of marketing and advertisement. The choice of language to convey specific messages with the intention of influencing people is vitally important. Visual content and design in advertisement have a very great impact on the consumer, but it is language that helps people to identify a product and remember it (Pullum, 2001).

To persuade people to buy the product is the main purpose of the advertising. Among such great 
competition, the producer wants to demonstrate the uniqueness of his product.Also, the advertisement texts must be more attractive and more unexpected. They must catch the attention of the audience and then identify the product. Advertisers create uncommon, surprising, interesting texts with catchy slogans or phrases. The reader or listener must give it some thought and the result is manipulation with him in order to buy the product (Lapsanska, 2006).

Therefore,both the mass media and advertisementcompany have to consider the emotive power of the words they use when reporting news items and marketing. They have to make a decision about what to communicate. One way in which advertisers adapt language to their own use is to take compound words and use them as adjectives. These compounds often later become widely used in normal situations. Examples of these compounds which have become part of the English language are: top-quality, economy-size, chocolate-flavored, feather-light and longer-lasting (Jeffrey, 1976).

While some advertisements act on pre experience mental states like awareness or intention to purchase, other advertisements influence what the consumer takes from the consumption experience itself. Some experiences resist verbal description. These experiences may generate weak, ambiguous, or uninterpretable cues. Or they may offer strongly felt cues which fit no ready categories in language because the cues are new, unfamiliar or unaccepted (El Day, 2011).

Accordingly, Cook (2005) said that, "Writing on advertising is difficult. The reasons are partly formal, arising from its ever-changing uses and combinations of language, pictures and music. They are also social and moral, for advertising arouses a greater strength of condemnation or support than most other contemporary discourses."

On the other hand, according to Jeffrey (1976), the language of advertisement, of course, normally emphasizes why one product stands out in comparison with another. However, advertisement language may not always be correct language in the normal sense. For example, comparatives are often used when no real comparison is made.

Additionally, the kind of language we use for advertisement in mass media, leading journals and newspapers has positive or negative impacts on the success of advertisement personnel and companies. Therefore, appropriate language use both in oral and print advertisements brings success. Otherwise, many advertisements may fail to persuade their target audiences. In case, organizations may fail to sell their goods, idea, services, and other properties through advertising, unless they make their advertisements in persuasive ways(Tanaka, K., 1990).

Some advertisements may use unrelated descriptions for the advertising goods. From the researcher knowledge and experience in reading print advertisements from many newspapers, some advertisements have unrelated contents and visual icons. On the other hand, the languageused in some of the advertisements was not much persuasive. Hence, the researcher believed that those problemsmight have negative impacts on the advertising company or producer.Thus, uunderstanding the stated problem has necessitated to conduct on this issue.

\section{OBJECTIVES OF THE STUDY}

\section{General Objective}

The main objective of this study is analyzing the discourse of print newspaper advertisements interims of linguistic features.

\section{Specific Objectives}

- To analyze the phonological aspects of the advertising language such as;rhyme, assonance, alliteration, and rhythm.

- To analyze the lexical aspects thosethe sample advertisements widely used. 


\section{RESEARCH METHODS}

In accordance with the research objectives, the researcher has made analysis on printednewspaper advertisements' language use.Thus,in order to get varied and well-prepared advertisements, Reporter Newspaper 2008, 2009 and 2010 E.c years of publications have been selected purposively.

On the other hand, as Reporter Newspaper is published twice a week, there are about 96 publications in each year.Therefore; from the total 312 number of publications in the selected three years, twenty monthsfrom the selected years have been selected randomly and from each selected months' publications, the first publication of each selected month which is appropriate for the study have been taken purposively.

Accordingly, from 2008,2009 and 2010 years of publications, twenty advertisements have been purposively selected; one advertisement was selected from each sample month'sfirst publication newspaper. Thus; twenty advertisementsare selected as samples and analyzed interims of their language use.

These sample advertisements wereselected in four categories:five of them from goods (products), five of them from business services, five of them from construction vehicles\& motors and five of them from housing and apartments. The varieties can easily help to analyze all kinds of printed advertisements.

\section{Data Collection Instrument}

The researcher believed that document analysis was the appropriate data collection method. Therefore, document analysis was used to collect the data from the sample newspapers.

\section{DATA ANALYSIS}

The main data analysis methods used were textual and content analysis. But textual analysis was more appropriate for this research. Textual analysis was used to analyze the linguistic features of advertisements specifically the descriptive parts of the samples.
As the researcher used qualitative research approach and the objective of this research was to analyze the discourse of printed advertisements, textual analysis method was used to analyze how the textsof the advertisements wereused to make persuasion.As Reporter Newspaper is published in Amharic and English languages, translation from Amharic to English language has been made for Amharic advertisements.

\section{THEORETICAL FRAME WORK}

\section{Textual Conceptual Functions}

The theory used for this study is the Textual Conceptual Functions (TCFs) of Lesley Jeffries (2016). Stylistic judgments are based on evidence from texts and use linguistic models to account for this analysis. This takes stylisticsto a critical perspective which functions in the text. Jeffries gives a description of the language of a text linked to a setof interpretations. This is explained in the Textual Conceptual Functions (Jeffries 2016) which has three types ofmeanings, which are the linguistic, the ideational and the interpersonal.

The linguistic meaning as explained in Jeffries(2016) includes the de-contextual, structural and semantic meanings that examine the levels of language which are phonology/graphology, morphology lexis, syntax, discourse. The linguistic meaning is the core meaning, fundamental to all language use. Hence, this research has been analyzed depending on the linguistic meaning.

\section{Critical Discourse Analysis (CDA)}

Discourse analysis on its own does not necessarily set out to be critical. Maingueneau (2006:230), however, makes a distinction between the "weak" and "strong" discourse analyses: the former entails a "simple description of structures of texts and talks" (such as content analysis), and the latter involves analysis of the connection between discourse and social structures (such as CDA). Similarly, Fairclough (1992) claims that "Critical" implies showing connections and causes which are hidden; it also implies intervention, for 
example providing resources for those who may be disadvantaged through change".

With a political stance, CDA explicitly explains the dynamics of power, knowledge and ideology that surround discursive processes (Phillips and Hardy, 2002:20). CDA also focuses on the role of discourse in the way that the abuses of power are constituted and sustained. Moreover, CDA explores the nature of persuasion, ideology, and conflict (Elliot, 1996; Fairclough, 1995; Fairclough and Wodak, 1997; Phillips and Hardy, 2002; van Dijk, 1996). In addition, CDA aims to analyze the "dialogical struggle (or struggles) as reflected in the privileging of a particular discourse and the marginalization of others" (Phillips and Hardy, 2002: 25). In a more practical way, CDA is useful for analyzing how communicative strategies are shaped by and help shape contexts.

\section{Fairclough's CDA Approach: A Three-Dimensional} CDA Framework

Fairclough's CDA approach focuses on studying discursive events; an event is an "instance of language use, analyzed as text, discursive practice, and social practice" (Fairclough, 1993, p.138). Therefore, a discursive event involves both texts, discursive practices (production and interpretation of the text), and social practices (including situational, institutional and societal practice).

Based on this idea and within a critical discourse tradition, Fairclough in his several influential works including Language and Power (1989), Discourse and Social Change (1992) and Critical Discourse Analysis (1995), proposed a three-dimensional framework that could be employed to relate micro levels of language use to wider aspects of social practice. Social practice can be analyzed using the construct of "order of discourse", which refers to the sum of all discourses that are in practice within a specific social domain or institution (such as the media, or the university (Fairclough, 1993). Every communicative or discursive event consists of three dimensions - text, discursive practice and social practice and should be analyzed accordingly:
Accordingly, based on the above theoretical frameworks, depending on the nature of my research samples I focused on analyzing only the textual parts (the linguistic features of the text including phonological aspects, lexical aspects, syntactic aspects and semantic aspects (figurative style).

\section{RESULTS AND DISCUSSIONS}

With the development of globalization and industrialization, more and more goods are produced in the world; as a result, advertisement plays an important role in selling products. It is an art of language using various kinds of devices. The advertisements have achieved amazing effects on persuading consumers to buy the products.

In many developed countries, magazines and newspapers are the daily materials for people to read. No matter where people are, on the buses or subways or during the break time or after meal, they can get whatever information they want in the magazines and newspapers. So magazines and newspapers have become one of the most effective ways of providing information, and the advertisements in magazines and newspapers can achieve good effects, they are noveldesigned, concise and colorful which are full of aesthetics and can be fast read in order to attract people's attention as much as possible, and arouse readers' strong purchasing desire and persuade them to buy the products.

Accordingly, to show the linguistic devices used in my sample advertisements, thedata is presented and analyzed based on the linguistic thematic issues of phonological aspects, lexical \& morphological aspects, syntactic aspects andsemantic aspects as follows.

\section{Phonological Aspects used in the Advertisements}

Advertising language often uses the techniques similar to those in poetic texts. The advantage of so-called mnemonic devices (rhyme, alliteration, assonance, consonance, rhythm, and onomatopoeia.) is the mnemotechnical effect. It guarantees that the receiver of the advertisement better remembers the text and recalls it at the right moment. 
One of the dominant sound techniques in English advertisement is rhyme, which, according to Cuddon (1999), is the formalized consonance of syllables. It should be noted that rhyme refers to the way the word is pronounced, not spelled. In Leech's (1972)view, rhyme makes advertisements, slogans and headlines appear striking and easier to remember.

Rhyme is a pattern of identity of sound between words or verse-lines extending from the end to the last fully accented vowel and not further. It refers to sounds, not spelling. It is commonly found in jingles, slogans and headlines (Concise Oxford English Dictionary, 2004). In Leech's (1972) view, rhyme makes the advertisement striking and easier to remember.Some of the sampled advertisements used this literary device; see the following extracts.

\section{Extract 1: Scooty Motorcycle}

Automatic speed controller,

Safety alarm and controller!

(Reporter Newspaper October 3, 2008; Vol. 21, No.1613)

\section{Extract 2: Zebidar Beer}

The beer opener,

Only your finger!

When we meet,

When our fun comes to hot!

(Reporter Newspaper; January 7, 2009, Vol. 22; No. 1744).
In the sample advertisements, specially presented at the above, rhyme is consisted by repetition of the ending sounds of the rhyming words. There is an echo in a rhyme and so it is a source of aesthetic satisfaction. There is pleasure in the sound itself and in the coincidence of sounds, and this pleasure is associated with the sense of music, of rhythm and beat, the pulse sense which is common to all human beings. Rhyme is a rhythmical device for intensifying the meaning as well as for binding the advertisement's text together. Especially, phrases tied together with rhyme are effectively used in the advertisements.

According to Ding (2003), rhyme is most probably the best sound technique used for the introduction of the brand name. If the brand name is not used in the advertisement, the advertisement, as Ding puts it, "is likely to lose its identity, because similar products can use thesame ad with a simple change of the product name". As suggested by the scholar, the function of rhymes in the form of slogans is the transmission of simple information. Hence, the rhyme used in the above extracts of advertisement (Scooty motorcycle and Zebidar beer) allows better memorization of the advertisements, as it resonates in one's mind.

Another dominant sound technique identified in the body of the sampled advertisements is alliteration. In his book, Cuddon defines alliteration as "a literary device in whichconsonants, especially at the beginning of words, or stressed syllables, and or phrases are repeated" (1999, 23).

These occurrences are appeared in the following advertisements. The bold letters represent the repeated consonant sounds. The advertisement is about Pluto Real estate. 


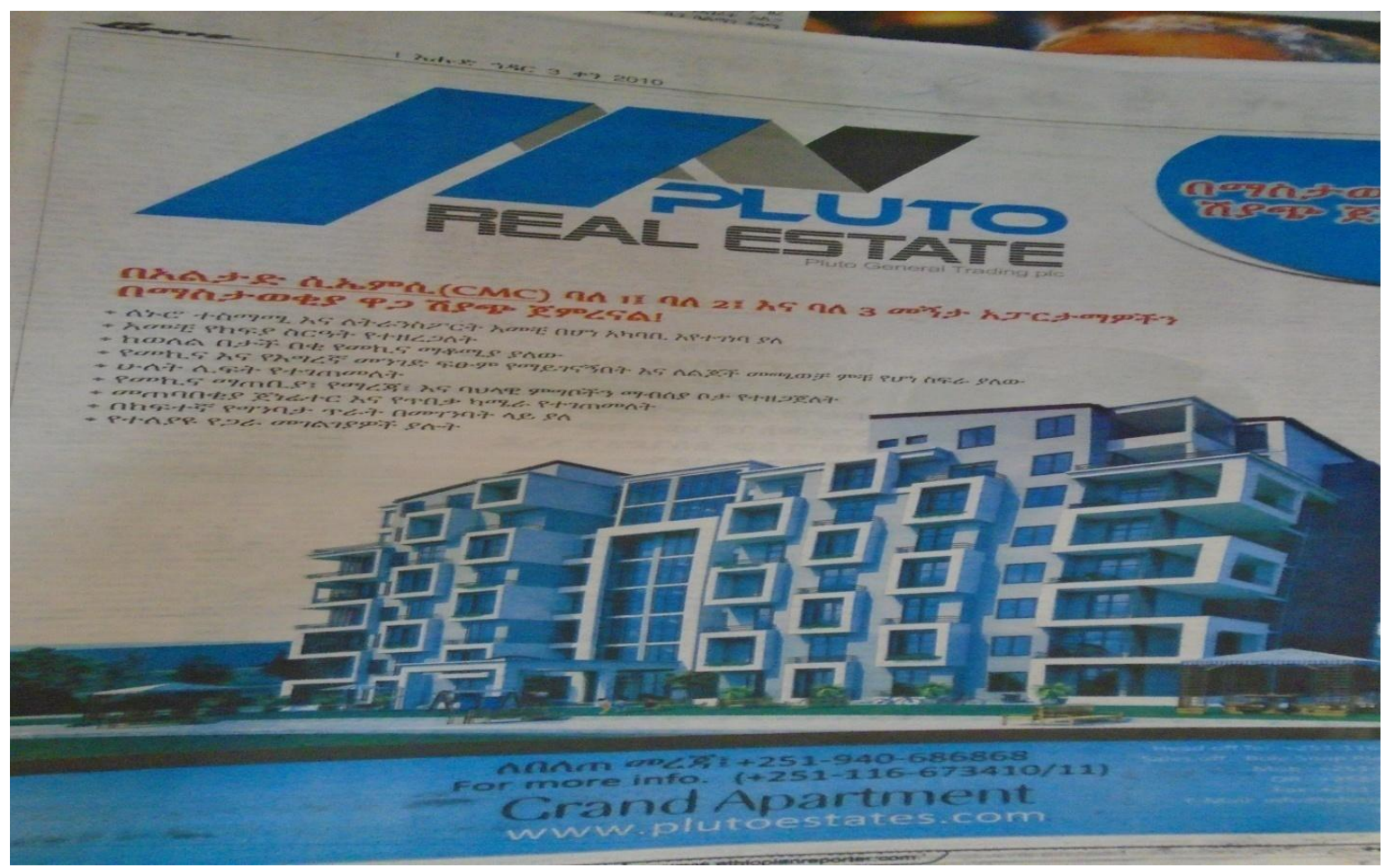

\section{Extract 3: Pluto Real Estate}

\section{PULUTO REAL ESTATE!}

We started selling through advertisement!

We started selling apartments with 1, 2 and 3 bed rooms, which are found at Altad CMC, through advertisement!

* It is building at comfortable residential and affordable transportation area,

- Has safe payment system, Has enough parking area at under the ground,

* Has isolated car road and pedestrian and has safe children's play ground,

* Has two lifts, Has enough car wash, slaughtering, and cultural food's kitchen place,

* Has standby generator and security camera,

* Has high building quality,

* Has a different common services material.

(Reporter Newspaper; November 3, 2010, vol. 23, no. 1830)

In his work, Myers (1997) states that in advertisements alliteration with its similarity in sound often plays against dissimilarity in meaning and makes the listener more aware of the contrast.

Sometimes referred to as "vocalic rhyme", assonance consists of the repetition of similar vowel sounds; usually close together, to achieve a particular effect of euphony(Cuddon,1999). As compared with alliteration, assonance is not very obvious in advertising slogans and is harder to identify.

\section{Adjectives}

While reading the advertisement, the reader may notice the hyperbolic characterof the language. This exaggeration causes increased number ofcomparative and superlative adjectives. The product is better, nicer, newer, andtighter and the 
customer is happier and more satisfied. The product offers moreinformation, more entertainment, more comfort, more than any other product.

Accordingly, wecan observe from the sampled advertisements used before; from Scooty, motorcycleadvertisement that gradable adjectiveslike:long,quick describequalities that can be measured in degrees; they can be used in comparative orsuperlative forms, and outnumber non-gradable adjectiveslike: central,automatic describe qualities thatare completely present or completely absent; they do not occur in comparative andsuperlative forms, and cannot be used with adverbs such as very or extremely,because we don't usually imagine degrees of more or less of the quality beingdescribed.

8100A

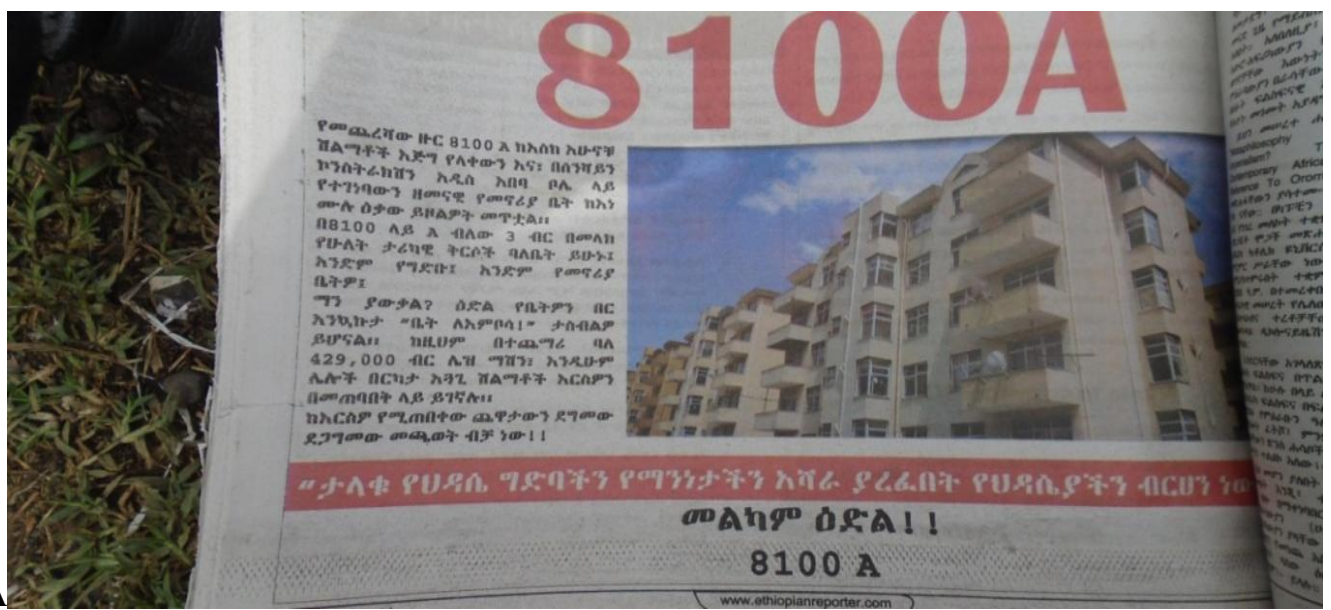

Extract 4: 8100A (The Ethiopian Great Renaissance Dam's Fundraising Advertisement)

Amharic version

$8100 \%$

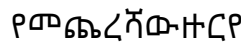

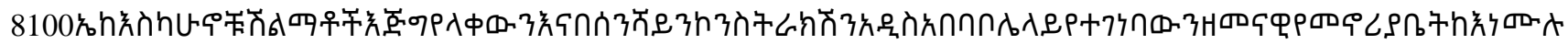

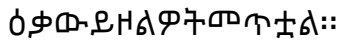

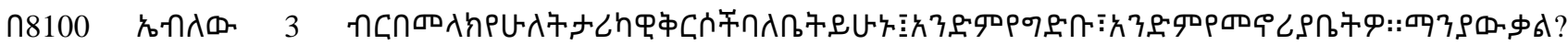

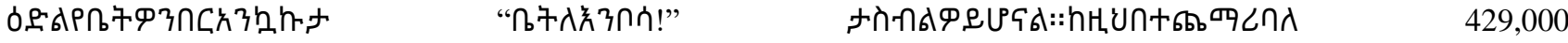

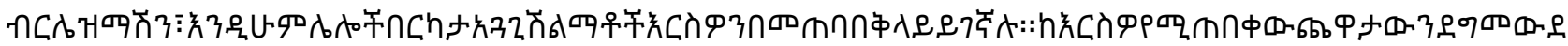

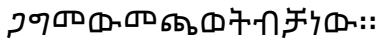

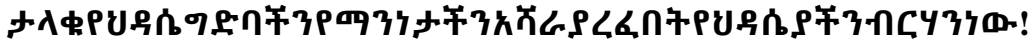

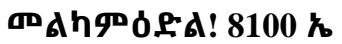

\section{Translated data/English version}

Look the words in bold letters in the following advertisements (see the English version/translated extract):

\section{A}

The final round of 8100 Abrought you the best prize of all the previous prizes that is a fully furnishedmodern residence which is built by Sunshine Construction in Addis Ababa at Bole. 
Send A to 8100 by 3 birr and be the owner of two historical heritages. One, the Great Renaissance Dam: and two, your residence.

Who knows? Luck may say to you "Congratulations on your new residence!" In addition, a 429,000 birr laze machine and many other thrilling prizes are waiting for you.

You are expected only playing the game repeatedly.

OUR GREATRENAISSANCE DAM IS THE LIGHT OF OUR RENAISSANCE IN WHERE OUR PRINT OF IDENTITY HAS BEEN REST!

\section{GOOD LUCK!!}

(Reporter Newspaper (April2, 2008; Vol. 21, No. 1664).

In the Advertisement, adjectives such as final,best,fully furnished, modern,historical,great,new,renaissance,thrilling,many andgood are used. These adjectives made the advertising product as a very interesting and hyperbolic character. They expressed the advertiser's evaluative and emotional attitude by emphasizing and describing the advertising product that is the Residence.

\section{Numerals}

In many advertisements, we can see the use of numerals. It is necessary if the copywriters want to define the characteristics of the product exactly. Numerals are used to define quantity of various aspects, for example percentage of some substance in a product, number of years in connection to the length of the tradition of the product, the number of satisfied customers, etc.

\section{Extract 5: Omedad}

A-CLASS sells register materials-in different models

$\checkmark \quad$ Fully confirmed by the new testing checklist standards of the Ethiopian Revenue and Tax Authority,

$\checkmark$ Comfortable to use,

$\checkmark$ Modern and use for all commercial fields,

$\checkmark \quad$ Can help to perform 100million of sells with a single receipt,

$\checkmark \quad$ They take only one paper,

$\checkmark \quad$ They can make automatic summary report (Z-report) and other above 20 sells summary reports. A-CLASS FROM OMEDAD -Your satisfaction is our proud!

(Reporter Newspaper March 3, 2009; Vol.22, No.1760).

We can easily look how numerical expression is used in order to quantify the advertisements and make clarification to the readers. The sample advertisement called 'Omedad', as listed at the above extract, is used numerical expressions like; 100 million, a single, one, and 20; it is tried to catch readers' attention towards the advertising product's quality and through these numerical expressions.

\section{CONCLUSIONS}

Advertising language is unique by itself. The way advertisements are made is different from other discourse types. Thus, in order to persuade readers to buy orto get the advertising goods /services, advertisers made advertisements through many persuasivetechniques.Most of the persuasive techniques in advertising are similar to those in poetics. These techniques can make the advertisement memorable and persuasive. 
Rhyme, assonance, and alliteration are mostly used in two advertisements ("Scooty Ignite" and "Zebidar beer"). On the other hand, rhythm is also occurred in an advertisement in which there are rhyme, alliteration and assonance. Graphical aspect of the text especially acronyms are also used in one of the advertisements that is EMS- for Ethiopian Mail Service and WU-for Western Union.

The lexical and morphological aspects of the linguistics means are also used in almost all of the sample advertisements. In this category, adjectives are widely used in most of the advertisements. As it is analyzed very well at the analysis part, the use of adjectives in advertisementsis much wider than other discourses. The reason is because adjectives have the power of giving exaggerated and hyperbolic character to the advertising goods and services. So; as these features can help advertisers to persuade their addressees, almost all of the above advertisements have used many gradable and non-gradable adjectives. Moreover, there are also numerical expressions in some advertisements. These numerical expressions helped to define quantities and exact number of the advertising products/services. On the other hand, noun phrases and verb phrases are also widely used. But noun phrases are more frequently used than verb phrases. These noun phrases are modified by many adjectives and other complements. Generally, the noun and verb phrases are structured as sentences without subjects or main verbs.

Generally, mostof the sample advertisements are written in many persuasive techniques, some of them used very fewpersuasive techniques. However, the kind of linguistic means used in all of the sample advertisements are effectively used. They made the advertisements attractive, precise, memorable and persuasive. Even though very few sample advertisements are written with very few linguistic features, the way they used the linguistic elements canattract and catch readers' attention in order to sell or promote the advertising goods or services.

\section{REFERENCES}

Ethiopian reporter Newspaper, (2008, 2009, 2010 E.C). A weekly published newspaper. Addis Ababa, Ethiopia.

Cook, G. (2005).The Discourse of Advertising. Routledge11 New Fetter Lane, London EC4P 4EE

Creswell, J. (2007). Qualitative Inquiry\&Research Design:Choosing Among Five Approaches (2nd ed.). London and New Delhi: Sage Publications

Cuddon, J. A. (1999). The Penguin Dictionary of Literary Terms and Literary Theory. London: Penguin Books Ltd.

Ding, X. (2003). Stylistic Features of the Advertising Slogan.

El-daly, H. (2011). Towards an Understanding of the Discourse of Advertising: Review of Research with Special Reference to the Egyptian Media

Goddard, A. (1998). The Language of Advertising. Written texts. London: Routledge

Jeffrey, S. (1976). The Language of Advertising Claims. Teachings about Doublespeak. (n.d)

Lakoff, G.\& Johnson, M. (1980). Metaphors We Live By. Chicago: The University of Chicago.

Lapsanska, J. (2006). The Language of Advertising withthe Concentration on the Linguistic Means And The Analysis Of Advertising Slogans. Bratislava Comenius University Bratislava Slovakia.

Leech, G, N. (1972). English in Advertising: A Linguistic Study of Advertising in Great Britain (English Language Series). London: Longman

Myers, G. (1997 ). Words in Ads. London: Hodder Arnold

Pride, W. \& Ferrell, O. (1987). Marketing Boston: Houghton Mifflin Co

Pullum, Geoffrey K., etals (2001). More than Words. Nature, 413, 27 September 2001

Quirk, and et al. (1990). A Student's Grammar of theEnglish Language. Harlow: Pearson Education Ltd.

Tanaka, K. (1992), "The Pun in Advertising: A Pragmatic Approach," Lingua, 87. 